\title{
ARTÍCULOS
}

\section{El giro antropológico en el pensamiento de José Ortega y Gasset. Del monismo culturalista de mocedad al pluralismo cultural de la razón histórico-vital*}

\author{
The anthropological turn in the thought of José Ortega y Gasset. From cultural \\ monism of youth to the cultural pluralism of the historical and vital reason
}

\author{
Alejandro de Haro Honrubia \\ Universidad de Castilla-La Mancha \\ alejandro.haro@uclm.es \\ ORCID iD: https://orcid.org/0000-0003-1936-3920
}

\begin{abstract}
RESUMEN: Las siguientes páginas versan sobre el giro antropológico que se produce en la obra de José Ortega y Gasset (1883-1955) en lo que sería el tránsito entre la razón moderna, a la que filósofo español se adhiere en su mocedad -época en que Ortega se decanta por la cultura occidental que con sus raíces en Grecia concibe como la cultura esencial-, y la razón histórico-vital, que, abierta a la pluralidad cultural, se impone en su pensamiento en los primeros años de la década de los años 20 del siglo que dejamos atrás. Frente a la razón moderna europeísta de su pensamiento inicial, Ortega propone en la década de 1920, un tipo de razón vital que incorpora la idea del sentido histórico que es el elemento que definirá de aquí en adelante su pensamiento antropológico. El monismo culturalista que el filósofo español elogiaba en sus primeros años como intelectual, deja paso con el tiempo a un pluralismo de culturas característico de la contemporaneidad.
\end{abstract}

Palabras clave: Ortega; Antropología; Cultura; Idealismo; Modernidad; Razó n pura; Razón histórico-vital.

Cómo citar este artículo / Citation: Haro Honrubia, Alejandro de (2021) "El giro antropológico en el pensamiento de Ortega. Del monismo culturalista de mocedad al pluralismo cultural de la razón histórico-vital". Isegoría, 64: e16. https://doi.org/10.3989/isegoria.2021.64.16

AвSTRACT: The following pages deal with the anthropological turn produced in the work of José Ortega y Gasset (1883-1955) in relation to the transit between the modern reason, to which the Spanish philosopher is joined in his youth - a period in which Ortega opts for the western culture as an essential one, due to the Greek roots of Europe-, and the historical and vital reason, which is open to the cultural plurality and dominates his thought from the beginning of the twenties on. Against the modern and pro-European reason of his initial thought, Ortega proposes in the 1920s, a type of vital reason that incorporates the idea of historical sense that is the element that will define his anthropological thought from now on. The cultural monism praised by the Spanish philosopher in his first years as highbrow, is replaced by a pluralism of cultures which is characteristic of the contemporaneity.

Keywords: Ortega; Anthropology; Culture; Idealism; Modernity; Pure reason; Historical-vital reason.

Recibido: 7 enero 2018. Aceptado: 1 diciembre 2020.

Copyright: (C) 2021 CSIC. Este es un artículo de acceso abierto distribuido bajo los términos de la licencia de uso y distribución Creative Commons Reconocimiento 4.0 Internacional (CC BY 4.0).

\footnotetext{
Este artículo se finalizó en el marco del Proyecto de investigación del Plan Nacional, «Redes intelectuales en Europa y América a través de los epistolarios de José Ortega y Gasset», que dirige el profesor José Varela Ortega, y que tiene la siguiente referencia: FFI2016-76891-C2-1-P. Agradezco la ayuda que en mis tareas de investigación siempre me han brindado los miembros de la Fundación José Ortega y Gasset/Gregorio Marañón de Madrid.
} 
La realidad histórica, el destino humano avanza dialécticamente, si bien esa esencial dialéctica de la vida no es, como creía Hegel, una dialéctica conceptual, de razón pura, sino precisamente la dialéctica de una razón mucho más amplia, honda y rica que la pura -a saber, la de la vida, la de la razón viviente-

En torno a Galileo, OC, VI: $480^{1}$

\section{PRESENTACIÓN Y JUSTIFICACIÓN DE LA ELECCIÓN DEL TEMA. ORTEGA, ENTRE LA RAZÓN PURA DE LA MODERNIDAD Y LA RAZÓN HISTÓRICO-VITAL DE LA CONTEMPORANEIDAD}

Las siguientes páginas versan sobre un aspecto que todavía no ha sido estudiado en el contexto de los estudios orteguianos, pero que es de radical importancia para comprender el devenir del pensamiento orteguiano. Me estoy refiriendo al giro antropológico ${ }^{2}$ que se produce en la obra de José Ortega y Gasset (1883-1955) en lo que sería el tránsito entre la razón moderna, a la que el filósofo español se adhiere en su mocedad en su intento de solución del problema nacional ${ }^{3}$ y la

Las citas de las obras de José Ortega y Gasset remiten a la edición de Ortega y Gasset, J. (2004-2010), Obras Completas, Madrid: Taurus/Fundación José Ortega y Gasset. En adelante, al título del escrito sigue en números romanos el tomo y en arábigos la(s) página(s).

2 Utilizamos la expresión, "giro antropológico" en un sentido tanto filosófico como cultural y en relación con los cambios que acontecen en la concepción que Ortega tiene sobre la cultura y la racionalidad. Con respecto al primero de estos ámbitos, tenemos que decir que en el pensamiento de Ortega sobresale en un primer momento la razón moderna -en la que aquel confía- sobrevalorando el pensador madrileño las virtudes de la Europa moderna filosófica y científica y también del hombre europeo u occidental cuyo modelo de perfección es el hombre de ciencia que representa el germano frente a otros modelos humanos. Sin embargo, en un segundo momento Ortega abandonará su eurocentrismo filosófico inicial defendiendo la existencia de diferentes perspectivas y formas de racionalidad. En lo que se refiere a la dimensión antropológica cultural, el cambio o giro responde principalmente a que en sus comienzos Ortega se vanagloria de la cultura europea que, con sus raíces en Grecia, y gracias a esta, aparece como la única cultura auténtica o verdadera, si bien en un segundo momento el filósofo español relativiza su posición inicial con respecto al papel de aquella en la historia universal, reconociendo una pluralidad de culturas en el mapa mundial.

3 El problema de España, al ser un problema de modernidad, se acaba reduciendo en el pensamiento de Ortega a un problema de alcance filosófico. En el periódico El Faro, el 8 de marzo de 1908, dice Ortega que el problema de España radica en que "por su alma no han pasado razón histórico-vital, que, abierta a la pluralidad cultural, se impone en su pensamiento en los primeros años de la década de los años $20 \mathrm{del}$ siglo que dejamos atrás, y desde la cual Ortega tratará de superar la modernidad, cambiando de opinión en torno a la centralidad que otorgaba a la cultura de la Europa occidental-europeísmo de juventud-.

Bien es cierto que en La rebelión de las masas (1930), especialmente en la segunda parte de esta obra, Ortega expresa nuevamente cierto europeísmo, pues apunta la idea de unos Estados Unidos de Europa, o lo que es igual, la pluralidad europea sustituida por su formal unidad: "La evidente decadencia de las naciones europeas, ¿no era a priori necesaria si algún día habían de ser posibles los Estados Unidos de Europa, la pluralidad europea sustituida por su formal unidad?" (¿Quién manda en el mundo?, OC, IV: 464). Y en El prólogo para franceses (1937) dirá Ortega lo siguiente: "La figura de ese Estado supernacional, será, claro está, muy distinta de las usadas como [...] ha sido muy distinto el Estado nacional del Estado-ciudad que conocieron los antiguos" (Prólogo para franceses, OC, IV: 355) ${ }^{4}$. Sin embargo, esta nueva idea europeísta de Ortega en su madurez intelectual no invalida nuestra tesis sobre el cambio de perspectiva que en su pensamiento se produce con respecto a la posición de Europa en el mapa mundial y en la historia universal.

El pensador madrileño modificará, como decimos, en la década de 1920 su pensamiento de mocedad que concedía exclusividad a Europa y concretamente a Alemania, a donde Ortega marchó en 1905 atraído por el neokantismo como sistema filosófico dominante en el país germa-

ni Platón, ni Newton, ni Kant, y con una terquedad incomprensible viene cometiendo, desde hace tres siglos, el gran pecado contra el Espíritu Santo: la incultura, el horror a las ideas y a las teorías" (La conservación de la cultura, OC, I: 152). Es la española, dice Ortega en 1912, una raza que se ha negado a realizar en sí misma "aquella serie de transformaciones sociales, morales e intelectuales que llamamos Edad Moderna". La historia moderna de España, afirma el filósofo, "se reduce probablemente a la historia de su resistencia a la cultura moderna" (Una visita Zuloaga, OC, I: 534)

4 En la fecha de 1954, dirá Ortega que, "Mi idea es, pues, que estamos estos años - los años en que habría que hacer una Europa unitaria - viviendo la etapa en que las naciones europeas se sienten más distintas y más distantes, en que cada pueblo, no por motivos concretos, sino por una gratuita y general antipatía no puede aguantar a los otros" (Cultura europea y pueblos europeos, OC, VI: 950). 
$\mathrm{no}^{5}$, dedicado como estaba a la recuperación de los estudios kantianos. Así dice Ortega que su maestro Hermann Cohen con su primera obra, publicada en 1871, "iniciaba la reivindicación de Kant: volver a Kant era volver a la fontana maternal de la cultura germánica" (Hermann Cohen, OC, I: 1015).

Ortega vio precisamente en la tradición filosófica alemana una vía de acceso a la primigenia cultura clásica griega -al clasicismo de la Antigüedad- tan elogiada por él en los comienzos de su producción intelectual. El espíritu alemán se halla, según aquel, próximo a Grecia, o lo que es igual, encierra hoy en sí la más elevada interpretación de lo humano o de la cultura europea, cuya clásica aparición la hallamos en Atenas. Gracias a Alemania -afirma Ortega en 1911"tenemos alguna sospecha de lo que Grecia fue" (El "pathos" del Sur, OC, II: 83).

Si tenemos en cuenta que, para Ortega, "bajo los cráneos de Leibniz y Kant" oteamos las ideas platónicas -siendo como es Platón una de las principales fuentes de inspiración de Ortega ${ }^{6}-$, no es de extrañar que el pensador madrileño diga en El Imparcial, el 21 de septiembre de 1911, que "la cultura germánica es la única cultura esencial que hoy existe, la única sustantiva" (Una respuesta a una pregunta, OC, I: 460).

Sin embargo, para Ortega, es la cultura griega a través del pensamiento alemán que la recupera, la única cultura auténtica o verdadera: "Solo ha habido en el mundo -dice el filósofo español en 1911- una cultura clásica, por la sencilla razón de que hay solo una cultura verdadera [...], y esta, evidentemente, nació solo una vez. Solo Grecia no es un pasado" (Problemas culturales. -Sobre la enseñanza clásica, OC, I: 471).

Pero Ortega corrige en un segundo momento de su producción este pensamiento inicial, su concepción etnocentrista o exclusivista en tor-

\footnotetext{
5 Sobre el neokantismo, véase el completo estudio de Ernst Cassirer, Hermann Cohen y Paul Natorp (1998).

6 Ortega cita a Platón en innumerables ocasiones en sus Obras completas. En su biblioteca personal encontramos varias obras de Platón: Platón (1914), Platonis Euthyphro; Apologia Socratis; Crito; Phaedo / post Carolum Fridericum Hermannum; recognovit Martinus Wohlrab. Ed. Stereotypa, Lipsiae: B. G. Teubneri, Steingaden; Platón (1920-1985), Oeuvres complètes; texte établi et traduit par Maurice Croiset. Paris: "Les Belles Lettres"; Platón (1931), Platón el divino: diálogos platónicos / traducción directa por Emeterio Mazorriaga. Madrid: Librería y Casa Editorial Hernando.
}

no a la idea de cultura, ya sea en su versión clásica griega o germano europea. En la década de 1920 el filósofo de la razón vital se opondrá a una concepción monocéntrica de la historia universal, que en un principio elogiaba, cuando decía en 1911 que solamente el helenismo puede conducir "a la historia universal, que es, ni más ni menos, la historia de la cultura" (Problemas culturales. -Sobre la enseñanza clásica, OC, I: 472), reemplazándola por una concepción policéntrica o más plural, y reconociendo así la existencia de una diversidad de culturas en el mapa mundial, consecuencia de la ampliación del horizonte étnico, cultural e histórico gracias a los avances logrados por nuevas ciencias, como la arqueología, la prehistoria o la etnología, a través de cuyas aportaciones Ortega combatirá el etnocentrismo impositivo occidental, favoreciendo el relativismo cultural.

No obstante, el pensador madrileño dista mucho de ser un pensador ingenuo y es por ello que, aunque valora positivamente el relativismo cultural ${ }^{7}$, nos hace ver la importancia de no caer en una situación absurda de nihilismo en el ámbito cultural que nos impida reconocer y valorar -se entiende, con sentido crítico- las distintas aportaciones culturales, aunque como él mismo dice en 1924, esto exige su previa comprensión: "La valoración de las distintas culturas, su jerarquización en una escala de rangos, supone la previa comprensión de todas ellas", es decir, "es menester que de esta fina comprensión se saquen consecuencias de orden estimativo" (Las Atlántidas, OC, III: 771).

El filósofo español también reconocerá en un segundo periodo de su pensamiento que el clasicismo que abrazó en su mocedad es muy limitado, sonando "a norma de provincia", es decir, una especie de aldeanismo, "el aldeano cree que todo el mundo es de su aldea" (En torno al coloquio de Darmstadt, 1951, OC, X: 377), afirmando, por el contrario que cada cultura $-\mathrm{y}$ no solamente la cultura clásica griega- ha gozado de una genialidad sobresaliente para algún tema vital. Y entonces, dice Ortega en 1924,

... de esa gigantesca inducción histórica que estas páginas postulan y anuncian, nacerá un nuevo clasicismo, muy diverso del que se arrastra estéril sobre el pensamiento moderno, un clasicismo verdaderamente ecuménico

\footnotetext{
Las posturas etnocentrista y relativista en el campo de la antropología han sido estudiadas, entre otros, por Javier San Martín (2009).
} 
de radio planetario. Cada época, cada pueblo será nuestro maestro en algo, será en un orden o en otro nuestro clásico. Cesará el privilegio arbitrario que otorgamos a nuestro rincón del espacio y el tiempo, privilegio que convierte en absurda superfluidad la existencia de pueblos y edades «bárbaros», «salvajes», etcétera. La «barbarie», el «salvajismo» adquirirán su punto de razón y de insustituible magisterio (Las Atlántidas, OC, III: 771) ${ }^{8}$.

Es en los primeros años de la década de 1920 cuando Ortega expone estas ideas en algunos de los trabajos más representativos de este periodo. Así por ejemplo, El tema de nuestro tiempo (1923); Las Atlántidas (1924); Las Ideas de León Frobenius (1924); La etnología y la historia. A propósito de las conferencias de Frobenius en Madrid. - El carácter orgánico de las culturas (1924) o El sentido histórico $(1924)^{9}$.

8 En sus primeros años como pensador, Ortega, sumido en el pensamiento evolucionista que todavía dominaba el ambiente intelectual de la Europa occidental, denigrará la idea de "barbarie" y el "salvajismo" por su vinculación al caótico mundo natural, para posteriormente reconocer su aportación a la cultura y a la civilización, al considerar a aquellos la fuente de que emanan estas dos. Ya desde 1912, Ortega propone, aunque sea muy tímidamente, que toda civilización o cultura "ficticia, ornamental, farsante" retorne, al objeto de renacer, "a la naturaleza original, a la bruta e inmediata [...], inmersión en el orangután inicial que el hombre lleva dentro", mostrándose Ortega conforme con ese "pasajero retorno al paternal chimpancé" (Véase Pío Baroja: Anatomía de un alma dispersa, OC, VII: 291). En La Nación, el 3 de agosto de 1924, una vez que Ortega se ha distanciado claramente de la filosofía de la cultura que sometía lo más natural en el hombre a sus potencias culturales, llegará a decir aquel que "toda cultura que no quiera anquilosarse, secarse y morir cuidará de conservar franca la comunicación con las energías subterráneas de lo precultural", así como que "el imperativo de claridad y humanidad que es el clasicismo tiene que ser compensado con una voluntad de mantener intacto nuestro subsuelo salvaje" (Los alemanes y lo infrahumano, OC, III: 705 y ss.). En 1948, dice Ortega que él no tiene la pretensión de no ser salvaje: "Estoy convencido de que sí lo soy en dosis sobremanera respetable [y así tiene que ser]" (Véase Sobre una nueva interpretación de la historia universal. Exposición y examen de la obra de Arnold Toynbee: A study of History, OC, IX: 1347).

9 Estos trabajos conectan con algunos otros escritos de plena madurez de Ortega, especialmente interesante resulta para nuestro tema el artículo publicado en la revista, "Logos", octubre-diciembre de 1941, donde dice Ortega: "No caben, pues, ya devaneos como los de Lévy-Bruhl, en que a nuestro pretendido «pensar lógico» se opone el pensamiento de los primitivos como un «pensar prelógico», cosa que siempre debió parecer monstruosa. Al averiguar que el pensar lógico es mucho más ilógico de lo que sospechábamos, se
A partir de entonces, Ortega se decanta claramente por una nueva forma de racionalidad vital que incorpora la idea del "sentido histórico", abandonando aquel el monismo culturalista característico del discurso filosófico de la modernidad -al que se sumó en su mocedad idealista-, por la idea de pluralidad.

Sobre la base de esta reflexión inicial, la hipótesis de trabajo que planteamos es la siguiente: El giro antropológico que se produce en el pensamiento de Ortega a la altura de los años 20, se traduce en la superación, por parte del filósofo español, del monismo culturalista "eurocentrista"/"helenista"/"germanista" de mocedad, reemplazándolo por un pluralismo de culturas propio de una razón historicista -con plena vigencia en la actualidad en nuestra sociedad postmoderna y multicultural- que se impondrá en sus escritos hasta el final de su producción intelectual: "Aceptamos, dice Ortega en 1924, el hecho de la discontinuidad y del pluralismo siempre que el ensayo de reducción monista trae consigo una violación de las diferencias radicales" (Las Atlántidas, OC, III: 768).

Sin embargo, con el reconocimiento de la pluralidad diferencial y estimativa de las diversas formas culturales e históricas, Ortega no está negando la idea de absoluto o de universalidad cuya competencia es de un pensamiento de razón pura como aquel reconocerá. Lo que tratará de hacer Ortega es integrar esta última subsumiéndola en la razón histórica como forma de racionalidad más acorde con la nueva realidad cuya principal característica es ser diversa y plural.

El siguiente párrafo de su trabajo Las Atlántidas de 1924 es lo suficientemente clarificador en relación con su posición ante ambas formas de razón:

Más allá de las culturas está un cosmos eterno e invariable [...]. Períodos y razas - o, en una

nos abren los ojos para advertir que el pensamiento primitivo es mucho más lógico de lo que se presumía. Desaparecen, pues, las diferencias absolutas entre un tipo del pensamiento y los demás que el hombre ha ejercitado en la historia y queda establecida entre ellos continuidad. $\mathrm{O}$ lo que es igual: que retirada la pantalla del pensar lógico como único representante del Pensamiento, nos aparece este en su autenticidad consistiendo por fuerza en alguna otra cosa que exclusivamente en identidad, no contradicción y tercio excluso. Porque, repito, que si el Pensamiento consistiese últimamente en la presencia de esos atributos, nos sería forzoso reconocer que no lo ha habido nunca. Y el hecho es que el hombre de un modo o de otro, queriendo o sin querer, con brío o tenuemente, ha pensado siempre" (Apuntes sobre el pensamiento. Su teúrgia y su demiurgia, 1941, OC, VI: 13-14). 
palabra, las culturas - son los órganos gigantes que logran percibir algún breve trozo de ese trasmundo absoluto. Mal puede existir una cultura que sea la verdadera cuando todas ellas poseen solo un significado instrumental y son sensorios amplísimos exigidos por la visión de lo absoluto [...]. Si ante un problema queremos reaccionar a la europea, tenemos que desentendernos de la aspiración a lo absoluto y orientarnos no en el ideal transhistórico de verdad, sino en la línea histórica de los gestos europeos. Viceversa, si ante un problema buscamos su solución absoluta, nos desentenderemos del módulo europeo e intentaremos muy deliberadamente, merced a una violenta reflexión, libertarnos de nuestro europeísmo. Esta reflexión que nos liberta de la limitación histórica es precisamente la Historia. Por esto decía que la razón, órgano de lo absoluto, solo es completa si se integra a sí misma haciéndose, además de razón pura, clara razón histórica (Las Atlántidas, OC, III: 772-773) ${ }^{10}$.

\section{EL MONISMO CULTURALISTA DEL PENSAMIENTO ORTEGUIANO EN EL PRIMER PERIODO DE SU PRODUCCIÓN INTELECTUAL}

En un primer momento de su producción intelectual, Ortega, como ya se comentó en la introducción de este trabajo de investigación, sucumbe al monismo culturalista que confiere exclusividad a la Europa occidental en el mapa mundial y también a sus grandes construcciones culturales, deificando el filósofo español la misma noción de cultura que concibe muy etnocéntricamente al valorar solamente las grandes producciones de Occidente:

Dios, en una palabra, es la cultura [...]; podría decirse que Dios, afirma Ortega en 1910, es el conjunto de las acciones mejores que han cumplido los hombres: el Partenón y el Evangelio, Don Quijote y la mecánica de Newton, la Revolución francesa y la Historia Romana de Mommsen, las cooperativas de consumo y el régimen parlamentario. Dios es lo mejor del hombre, lo que le enorgullece, lo que intensifica su energía espiritual, la herencia científica y moral acumulada lentamente en la historia ( $\mathrm{La}$ teología de Renán, OC, I: 334).

10 Ortega oteó la idea de la razón histórica en Dilthey, donde dice aquel que este se quedó. Véase el trabajo de Gadamer, H.-G., (1985), "Ortega y Dilthey", Revista de Occidente, nos 48-49, pp. 77-88. Véase también Dilthey (1986).
Ortega se vanagloria de las virtudes europeas en el ámbito de la ciencia, de la cultura y del conocimiento en detrimento de otros pueblos -que localizamos en otros territorios no europeosque carecen de estos elementos y que se vinculan desde hace tiempo a prácticas de superstición, magia o religión al encontrarse -según se piensa- en un estadio evolutivo retrasado que dista mucho del conocimiento científico que se vincula etnocéntricamente a una sola civilización: "La civilización, la cultura, es una e indivisible" (Notas de Berlín, OC, I: 52), apostilla Ortega en 1905. Europa es, para el pensador español, la civilización de la razón científica y el progreso. No oculta Ortega su adhesión a la Europa moderna de la ciencia, al culturalismo y al racionalismo, aunque sea un racionalismo sui generis. En El Imparcial, el 11 de mayo de 1908, sella Ortega la siguiente reflexión:

¡Bien podía haber influido más en nosotros el Taine de la Estética y menos el Taine de la "Política! Pero ha ocurrido todo lo contrario y los conservadores abusarán largo tiempo aún de tal autoridad para echarnos en cara nuestro racionalismo - ¡como si fuera una peste!- a los que no estamos conformes con la realidad actual y evocamos otra más discreta y más justa (A. Aulard: "Taine, Historien de la Révolution Française”, OC, I: 172).

La afinidad intelectual de Ortega con el racionalismo o el mundo de la razón y el pensamiento científico se puede vislumbrar en una de las cartas que el filósofo español envió a la por entonces su novia Rosa Spottorno, el 12 de junio de 1907 desde Marburgo, burgo del neokantismo, donde le dice a esta lo siguiente:

Hay dos mundos, el mundo de la sensación y el de la verdad; aquel es momentáneo como la sensación, este eterno, el mundo normal, el mundo de $2+2=4$, cuya igualdad sigue siéndolo esté uno triste o alegre. Este mundo de la verdad, de lo que es en verdad -diría Platón-, es el que vivimos cuando pensamos científicamente, el otro es el que construimos con nuestro buen o mal humor [...]. Si mi vida intelectual se entrega a este mundo, mi vida intelectual no será verdadera, no estará conforme con lo que las cosas son en verdad: en cambio, cuanta mayor energía de régimen científico logre, será mi vida intelectual más fuerte, más honda y verdadera (Ortega y Gasset, 1990, p. 556). 
Ortega, como vemos en esta última reflexión, pone todas sus esperanzas de mocedad en una racionalidad pura matemática y científica que vincula a la cultura europea: "Europa -dice Ortega en 1908- es igual a ciencia; todo lo demás le es común con el resto del planeta" (Asamblea para el progreso de las ciencias, OC, I: 186). Como contrapunto a Europa, Ortega refiere el retraso científico de España, que simboliza para él la inconsciencia. La decadencia española "consiste pura y simplemente en falta de ciencia, en privación de teoría", dice Ortega en 1911, lo que genera una enorme desazón en el filósofo español. De ahí que este afirme lo siguiente: "Verdaderamente se vio desde el principio que España era el problema y Europa la solución" (La pedagogía social como programa político, OC, II: 102).

Se trata de un europeísmo germanófilo, pues, como dice el filósofo en 1905, "Alemania es precisamente la nación cuya influencia en la dirección moral e intelectual nuestra habrá de sernos más fecunda [...]. He aquí lo que nosotros tenemos que aprender en Alemania y solo aprenderemos en ella: el modo de hacernos españoles en poco tiempo, el gran secreto alemán, el método" (Notas de Berlín, OC, I: 51). La ciencia y la cultura alemanas, como núcleo de las europeas, se convertían en la reflexión orteguiana, en un antídoto contra el achabacanamiento intelectual de los españoles. Europa, liderada en el campo científico y filosófico por Alemania, no es, afirma Ortega, una negación solamente. Es "un principio de agresión metódica al achabacanamiento nacional [...]. El símbolo Europa como metódica agresión, como fermento renovador que suscite la única España posible" (Nueva Revista, OC, I, 340). En El Imparcial, el 21 de septiembre de 1911 dice también Ortega que "la cultura germánica es, en primer lugar, predominantemente científica; y, en segundo lugar, la ciencia alemana es predominantemente metódica" (Una respuesta a una pregunta, OC, I: 462 $)^{11}$.

La cultura alemana como símbolo de la cultura europea hinca, como esta, sus raíces -y esto es lo que más interesa a Ortega- en la cultura clásica griega que, como ya dijimos, es para el filósofo español la cultura esencial, verdadera o

\footnotetext{
11 Ortega diferencia entre dos Alemanias: "digamos que hay una Alemania del filósofo y otra Alemania del filisteo, del burgués". La Alemania del filósofo, del sabio, del pensador, "no se mezcla jamás con la Alemania del filisteo", que se caracteriza por la incultura, la vulgaridad de espíritu y "la pobreza de energías" (Las dos Alemanias, OC, I: 134-135).
}

auténtica. No asimilarse la cultura griega, dice Ortega en 1910, "equivale a ser menos hombre, y significa una mayor aproximación al canguro" (La teología de Renán, OC, I: 334). En El Imparcial, el 28 de octubre de 1907, Ortega señala que "se ha mostrado un gran desdén hacia lo clásico [...]. Tras ese vocablo alienta místicamente la realidad más granada y plenaria, pues tengo a lo clásico, no solo por el embrión de la cultura, sino por el sentido perenne de ella" (Sobre los estudios clásicos, OC, I: 117-188) ${ }^{12}$. En fin, para Ortega, como ya dijimos, solo ha habido en el mundo una cultura clásica, una cultura verdadera -una sola aritmética, una sola física, una sola lógica, una sola ética- que localizamos en Grecia (Véase Problemas culturales. -Sobre la enseñanza clásica, OC, I: 472).

Esta sobrevaloración que realiza Ortega de la cultura clásica griega en los inicios de su pensamiento $^{13}$ tiene la peculiaridad, contrariamente a lo que el teórico español pensará en su madurez intelectual, de que deviene, antropológicamente hablando, en exceso etnocéntrica, así como resulta despectiva hacia otros grupos humanos de otros tiempos y espacios, al considerarlos inferiores en la escala evolutiva de lo humano. Dice Ortega en 1907, que "el hombre cultivado nació en Grecia y lo ayudó a bien nacer Sócrates -del filósofo griego dice Ortega que nos ha traído la definición y el método inductivo, o sea: la ciencia-, el partero equívoco y vagabundo", así como añade el filósofo madrileño que, "como en Siringa se hizo la bestia Pan, Dios-Pan, se hizo hombre en Grecia la bestia blanca. Sin la disciplina helénica solo hubiera sido una posibilidad más hacia lo humano, como lo fueron la bestia metafísica asiática o la bestia totemista de África. Fue preciso que llegara la claridad de Grecia para que los nervios del antropoide alcanzaran vibraciones científicas y vibraciones éticas, en suma, vibraciones humanas" (Sobre los estudios clásicos, OC, I: 117)

12 Clasicismo, dice Ortega en 1907, solo hay uno, "clasicismo griego, y los renacimientos serán siempre, forzosamente, un volver a nacer de Grecia, un volver a abrevarse en la energía perenne de las ruinas helénicas, «más perennes que el bronce»". Si el clasicismo "es el sentido íntimo de la cultura, es el humanismo greco-latino el clasicismo de las formas de la cultura y muy especialmente de las formas mediterráneas de la cultura" (Sobre los estudios clásicos, OC, I: 118-119).

13 Dice el filósofo en 1911, que lo clásico es "lo que no ha pasado ni ha muerto, antes bien, lleva en sí el perpetuo manadero elemental de las energías espirituales, lleva en sí la fuente de la vida" (Problemas culturales. -Sobre la enseñanza clásica, OC, I: 467). 
En El Imparcial, el 27 de julio de 1908, Ortega vuelve sobre la misma idea cuando afirma lo siguiente: "Si Europa trasciende en alguna manera del tipo asiático, del tipo africano, lo debe a la ciencia: el europeo no sería, de otro modo, sino una bestia rubia junto a las bestias más pálidas y de bruno pelo que pueblan el Asia, junto a la bestia negra y rizada de Goa y Victoria-Nyanza" (Asamblea para el progreso de las ciencias, OC, I: 186).

Ortega elogia, en detrimento de otros pueblos, las culturas europea y clásica griega, que vincula al conocimiento científico, pero también al deber ser moral que aquel identifica con la idea de sabiduría -recordemos el intelectualismo moral socrático- y la antigua idea de virtud. Recurriendo a Platón, dice Ortega en 1908 que para el gran filósofo griego "la virtud puede ser adquirida, puede ser enseñada, porque es conocimiento, es ciencia" (Sobre una apología de la inexactitud, OC, I: 222). No es la pureza, dice Ortega en 1908, "el primer deber del hombre, sino la sabiduría, no es la lujuria el gran pecado, sino la ignorancia" (La moral visigótica, OC, I: $168)^{14}$

Desde 1911, una vez que Ortega comienza a abandonar la "prisión" del neokantismo -como dijo que hizo en el Prólogo para alemanes (1934) - y se inicia desde 1912 en el estudio de la fenomenología con su idea del mundo de la vida (Lebenswelt), el filósofo español recula en lo que sería el papel hegemónico de la cultura del ideal científico y moral, si bien es verdad que no por ello dejará de valorar la importancia de la cultura del conocimiento a través del concepto de la tradición germana -que recupera la tradición intelectualista clásica-, a la que continúa encomendándose tratando de encontrar una solución al problema de España. Ortega seguirá confiando en la Alemania filosófica y así dice en 1915 que "no se confunda la cuestión de una influencia intelectual de Alemania sobre España con la de una alianza política. Aquella me parecía y me sigue pareciendo la única esperanza de restauración étnica de España, esta me parecía una cosa sin sentido" (Una manera de pensar, OC, I: 913).

Siguen, por tanto, quedando restos de germanismo en su pensamiento. En 1914, en Medita-

\footnotetext{
14 A través del neokantismo y sobre todo gracias a su maestro Paul Natorp -gran lector de Platón-, Ortega accedió al pensamiento del filósofo apodado "de las anchas espaldas", que representa para él la esencia del pensamiento clásico griego.
}

ciones del Quijote, se puede observar claramente la apuesta de Ortega por la cultura germana del concepto como instrumento a través del cual obtener seguridad y/o claridad en medio del caos vital. Ortega se decanta por la labor del concepto como sinónimo de labor de cultura, pues "la cultura no es la vida toda, sino solo el momento de seguridad, de firmeza, de claridad", siendo el concepto un instrumento, "no para sustituir la espontaneidad vital, sino para asegurarla" (Meditaciones del Quijote, OC, I: 786). El concepto, afirma el filósofo español, no puede ser como una nueva cosa sutil destinada a suplantar las cosas materiales. La misión del concepto "no estriba, pues, en desalojar la intuición, la impresión real. La razón no puede, no tiene que aspirar a sustituir la vida". Esta misma oposición, dice Ortega en 1914 y en respuesta a Miguel de Unamuno, "tan usada hoy por los que no quieren trabajar, entre la razón y la vida es ya sospechosa. ¡Como si la razón no fuera una función vital y espontánea del mismo linaje que el ver o el palpar!" (Meditaciones del Quijote, OC, I: 784). La labor de la razón, del concepto o el intelecto adquiere en su pensamiento en este momento una función de tabla de salvación de la realidad vital nacional, pues como dice Ortega: "Conviene a todo el que ame honrada, profundamente la futura España, suma claridad en este asunto de la misión que atañe al concepto [...]. Sería, pues, oportuno que nos preguntásemos: cuando además de estar viendo algo, tenemos su concepto, ¿qué nos proporciona este sobre aquella visión?" (Meditaciones del Quijote, OC, I: 782-783).

Que Ortega valore intelectualmente como positiva la figura del concepto al conferir este claridad en el desorden de la realidad vital -Ortega se referirá especialmente a la circunstancia nacional o española que en el mapa moral de Europa representa el extremo predominio de la impresión, no habiendo sido nunca el concepto nuestro elemento-, al servicio de la cual aquel debe estar ${ }^{15}$, nos conduce a pensar que la tradi-

\footnotetext{
15 Desde 1911, Ortega comienza a hacer un guiño a la idea de la vida: "La religión y la poesía son para la vida" (Arte de este mundo y del otro, OC, I: 436). En el pensamiento del filósofo el concepto de vida también sufrirá cambios. En un primer momento, un Ortega "idealista", presenta "un concepto de vida más general, pero más metódico. La vida, de una cosa, dice aquel en 1910, es su ser. ¿Y qué es el ser de una cosa? [...]. La esencia de cada cosa se resuelve en puras relaciones" (Adán en el paraíso, OC., II: 66). En un segundo periodo, Ortega concibe la vida aunque esta presenta diversos matices, como por ejemplo el hecho de que el filósofo la llegue a vincular al campo
} 
ción gnoseológica europeísta/germanista permanece -aunque sea solamente en este aspecto- todavía viva en su pensamiento, aun cuando bien es verdad que el filósofo español se ha propuesto como proyecto intelectual desde 1913-14 la superación de la Modernidad ${ }^{16}$.

La superación del idealismo de la Moderni$\operatorname{dad}^{17}$, del logocentrismo y del europeísmo culturalista que abrazó en su mocedad, se convertirá de aquí en adelante en la gran tarea filosófica de Ortega, como él mismo señalará cuando afirme en 1916 lo siguiente: "No soy nada moderno; pero muy siglo XX" (Nada moderno y muy siglo $X X$, OC, II: 167). Su oposición al pensamiento moderno idealista se convertirá en el principal leit motiv de su ensayo El tema de nuestro tiempo (1923), donde Ortega dice lo siguiente:

La razón pura no puede suplantar a la vida: la cultura del intelecto abstracto no es, frente a la espontánea, otra vida que se baste a sí misma y pueda desalojar a aquella. Es tan solo una breve isla flotando sobre el mar de la vitalidad primaria. Lejos de poder sustituir a esta, tiene que apoyarse en ella, nutrirse de ella como cada uno de los miembros vive del organismo entero (El tema de nuestro tiempo, OC, III: 592).

En su oposición a la Modernidad filosófica, Ortega no prescinde del intelecto o razón. Considera que esta es una adquisición eterna. Por ello,

de lo biológico- de forma más realista, es decir, como interacción de un yo con su circunstancia más inmediata, pues: "Yo soy yo y mi circunstancia, y si no la salvo a ella no me salvo yo", afirma Ortega en 1914 (Meditaciones del Quijote, OC, I: 757). A partir de 1929, la vida se convertirá en la realidad radical: "El nuevo hecho o realidad radical es «nuestra vida», la de cada cual. Intente cualquiera hablar de otra realidad como más indubitable y primaria que esta y verá que es imposible" (¿Qué es filosofía?, OC, VIII: 361).

16 La superación de la modernidad filosófica (del racionalismo y del idealismo) se convertirá para Ortega en el tema de nuestro tiempo, si bien es verdad que lo moderno como sinónimo de ciencia y teoría, o las virtudes intelectuales del concepto, le seguirán atrayendo. El filósofo español tratará de implementar la ciencia y el conocimiento en un país como España que ha carecido de aquellos elementos.

17 No hay que olvidar que para Ortega toda superación es negación, pero toda negación es también conservación, como recuerda él mismo con la mirada puesta en Hegel. Dice Ortega: "Hegel vio muy bien que en todo lo vivo - la idea o la carne - superar es negar; pero negar es conservar" (El Quijote en la escuela, OC, II: 424). El "ideal de la salud", que para el filósofo supone la liberación de todas las fórmulas inestables y excéntricas, implica también, junto a su negación, la conservación de las mismas. en su trabajo, Ni vitalismo ni racionalismo, de 1924, dice el filósofo español que "mi ideología no va contra la razón, puesto que no admite otro modo de conocimiento teórico que ella: va solo contra el racionalismo" (Ni vitalismo ni racionalismo, OC, III: 718), del que como vimos presumía en su mocedad.

Ortega en estos momentos, realizando un giro con respecto a su pensamiento inicial, se opone al logocentrismo racionalista de la Modernidad, afirmando que la razón que "un día, en las plazuelas de Atenas", Sócrates descubrió, y que ha imperado desde entonces y sin oposición en el mundo occidental, que amparándose en el poder de la razón se ha creído superior, debe abandonar sus pretensiones absolutistas y convertirse en un instrumento al servicio de la vida:

La razón es solo una forma y función de la vida. La cultura es un instrumento biológico y nada más. Situada frente y contra la vida, representa una subversión de la parte contra el todo. Urge reducirla a su puesto y oficio. El tema de nuestro tiempo consiste en someter la razón a la vitalidad, localizarla dentro de lo biológico, supeditarla a lo espontáneo. Dentro de pocos años parecerá absurdo que se haya exigido a la vida ponerse al servicio de la cultura. La misión del tiempo nuevo es precisamente convertir la relación y mostrar que es la cultura, la razón, el arte, la ética quienes han de servir a la vida [...]. La razón pura tiene que ceder su imperio a la razón vital (El tema de nuestro tiempo, OC, III: 592 y s).

La razón vital, como mostraré en el siguiente apartado de este trabajo, previo a las conclusiones del mismo, es también razón histórica, abierta a la pluralidad o diversidad de perspectivas -el perspectivismo orteguiano- y por tanto contraria a todo punto de vista absolutista o $s u b$ specie aeternitatis.

El individuo, para conquistar el máximum posible de verdad, no deberá, como durante centurias se le ha predicado, suplantar su espontáneo punto de vista por otro ejemplar y normativo, que solía llamarse «visión de las cosas sub specie aeternitatis». El punto de vista de la eternidad es -dice Ortega en 1923ciego, no ve nada, no existe. En vez de esto, procurará ser fiel al imperativo unipersonal que representa su individualidad. Lo propio acontece con los pueblos. En lugar de tener por bárbaras las culturas no europeas, empezaremos a respetarlas como estilos de enfrenta- 
miento con el cosmos equivalentes al nuestro. Hay una perspectiva china tan justificada como la perspectiva occidental (El sentido histórico de la teoría de Einstein, OC, III: 647-648) ${ }^{18}$.

\section{DEL ETNOCENTRISMO CLASICISTA $Y$ GERMANIZANTE DE MOCEDAD AL PLURALISMO DE CULTURAS CARACTERÍSTICO DE UNA RAZÓN HISTÓRICA Y VITAL}

Como hemos visto, en un primer periodo de su producción intelectual, un Ortega europeístal germanista, por su afinidad con el pensamiento neokantiano alemán, asume como propio el monismo cultural característico del discurso filosófico de la Modernidad, considerando que la única cultura auténtica, verdadera o esencial es la cultura clásica griega que recuperan algunas mentes germanas como, por ejemplo, Leibniz y Kant, siendo especialmente este último un referente para Ortega en su mocedad. El filósofo español refiere desde muy temprano la crítica de la razón práctica o la moral como ciencia. Es, en efecto, dice Ortega en 1908, "absolutamente falso que no se haya hecho nada en el terreno de la filosofía después de la Crítica de la razón pura. Luego de esta obra, publicada en 1781, se compuso el Fundamento de la metafísica de las costumbres (1785) y la Crítica de la razón práctica (1788), ambas por el mismo Kant. La Crítica de la razón pura es una obra genial", pero "lo nuevo en filosofía lo trajeron los dos libros siguientes citados: la moral como ciencia" (Sobre la pequeña filosofía, OC, I: 164).

Para Ortega, la Europa ilustrada de Kant y en general la modernidad eran precisamente símbolo de progreso científico y moral. A tenor de estas ideas de mocedad, vimos que para Ortega la Europa de la ciencia y del imperativo moral representaba la

\footnotetext{
18 La razón o perspectiva occidental de las cosas no es la única existente, pues todo pueblo o cultura tiene su porciúncula de razón, su perspectiva cósmica, así como aglutina su porción de verdad: "todas las épocas y todos los pueblos han gozado su congrua porción de verdad, y no tiene sentido que pueblo ni época algunos pretendan oponerse a los demás, como si a ellos solos les hubiese cabido en el reparto la verdad entera" (El tema de nuestro tiempo, OC, III: 613). La sola perspectiva falsa "es esa que pretende ser la única. Dicho de otra manera: lo falso es la utopía, la verdad no localizada, vista desde «lugar ninguno» (El tema de nuestro tiempo, OC, III: 614). Cada individuo, dice Ortega, "es un punto de vista esencial. Yuxtaponiendo las visiones parciales de todos se lograría tejer la verdad omnímoda y absoluta" (El tema de nuestro tiempo, OC, III: 616).
}

cima de la civilización o de la humanidad, restando el filósofo español sustancia histórica y cultural a aquellos pueblos no europeos a los que se refería en su juventud con el calificativo de "bestias", es decir, pueblos salvajes o bárbaros inmersos en el caótico mundo de la naturaleza propio de un estado evolutivo retrasado y regidos por los imperativos de aquella. Es a aquel mundo de lo natural al que se debe imponer, como ya decía Kant, y Ortega le seguirá en su mocedad, el mundo de la cultura, es decir, se trataría de cumplir con el deber de hacerse digno de la humanidad "por medio de la cultura en general, el deber de procurarse o de fomentar la capacidad de realizar todos los fines posibles, en cuanto esta solo se encuentra en el hombre; es decir, un deber de cultivar las disposiciones incultas de su naturaleza, como aquello a través de lo cual el animal se eleva a hombre: por consiguiente, un deber en sí mismo. Solo que este deber es únicamente ético" (Kant, 1989: 245).

Sin embargo, en un segundo momento, cuando Ortega ya ha dejado claramente atrás la "prisión" del neokantismo y del idealismo o culturalismo, esto es, cuando su europeísmo filosófico ya no es el mismo, no sintiendo Ortega por él una fe viva sino una fe inerte o muerta ${ }^{19}$, es decir, en los primeros años de la década de 1920, el filósofo español cambia sustancialmente de opinión. Se opone en la fecha de 1924 a la concepción moderna y progresista de la historia que en un primer momento compartía. Según afirma en estos momentos Ortega, bajo el yugo de aquella concepción, cuando un pueblo parecía no haber contribuido al progreso, se le negaba "positiva existencia histórica y quedaba descalificado como bárbaro o salvaje. Ahora bien; ese progreso era simplemente el desarrollo de las aficiones específicamente europeas: las ciencias físicas, la técnica, el derecho racionalista, etcétera" (Las Atlántidas, OC, III: 765).

La modernidad en Europa era, en efecto, símbolo de fe en el progreso. Se creía, como dice Ortega, que la humanidad había por fin montado en un convoy llamado cultura, el cual, por necesidad mecánica, había de llevarla en incesante avance a formas de existencia cada vez mejores "y así hasta el infinito. La fuerza creadora de esa cultura progresiva o progrediente era la razón, la inteligencia". El europeo no entendía más historia, como afirma el filósofo español, que la que iba movida por "la

\footnotetext{
19 Creemos en algo con fe viva, dice Ortega en 1935, "cuando esa creencia nos basta para vivir, y creemos en algo con fe muerta, con fe inerte, cuando, sin haberla abandonado, estando en ella todavía, no actúa eficazmente en nuestra vida" (Historia como sistema, OC, VI: 50).
} 
idea del progreso, la que consiste en el servicio de una cultura creciente" (Abenjaldún nos revela el secreto (Pensamientos sobre África menor), OC, II: 762). El progresismo occidental, gravemente afectado de etnocentrismo, conducía a que porciones gigantescas de vida humana, en el pasado y aun en el presente, "nos fueran desconocidas y los destinos no europeos que llegaron a ser noticia fueran tratados como formas marginales de lo humano, como accidentes de valor secundario, sin otro sentido que subrayar más el carácter substantivo, central, de la evolución europea" (Las Atlántidas, OC, III: 765).

Como crítico de la Modernidad, Ortega abandona ahora esta idea de una supuesta superioridad de la cultura europea en la que creía en su mocedad. Su concepción monocéntrica de la historia universal deja paso -recordemos que esta es nuestra hipótesis de trabajo- a una concepción de la historia policéntrica, al compás de la ampliación del horizonte histórico gracias a los descubrimientos especialmente de dos nuevas disciplinas como son la prehistoria y la etnología:

... jóvenes disciplinas avanzan y atraen la curiosidad de los mejores. Así - dice Ortega en 1924la prehistoria y la etnología. Estas dos ciencias de última hornada, aun en su iniciación, han dilatado incalculablemente la línea del horizonte histórico en las dos dimensiones de espacio y tiempo. Si antes la historia era casi exclusivamente la historia del Mediterráneo, hoy se extiende horizontalmente a todo el planeta. Parejamente, en la dimensión vertical, las excavaciones y el estudio etnológico de residuos culturales en los pueblos primitivos han agrandado cronológicamente el ámbito histórico. ¡Qué son los seis mil años de la historia tradicional, comparados con las vastas lontananzas de la prehistoria! (Las Atlántidas, OC, III: 756).

Ortega en estos momentos, una vez que ha abandonado la concepción idealista y europeísta de la cultura y la historia universal en beneficio de una concepción más plural y aperturista, muestra su admiración por el progreso de la etnología ${ }^{20}$, pues esta ciencia ha ocasionado, "una transmuta-

20 Para una historia de la etnología, véase Lowie (1946). Ortega también refiere el término etnografía. En 1922, el filósofo se opone al hecho de que la civilización europea apareciera, no como una civilización entre otras, sino como la "civilización", reconociendo este error de perspectiva y afirmando que ahora, "dos nuevos términos de comparación -orientalismo y etnografía- vienen a agrandar colosalmente el campo visual". Véase Temas de viaje (Julio de 1922), OC, I: 911. ción radical en nuestra idea de la cultura". Mientras teníamos del cosmos histórico, dice el filósofo español, una visión provincial, mediterránea y europea, "cultura quería decir una cierta manera ejemplar de comportarse. No había más que una cultura, la nuestra, del presente. La Edad Media, Grecia, Roma, Egipto, eran solo etapas al través de las cuales se había llegado a la actual perfección. Cualquier otro sistema de formas religiosas, intelectuales, políticas, era automáticamente desvalorado como inculto. Habíamos, pues, hecho de la cultura un concepto estimativo y una norma". Pero el etnólogo, desde mediados del siglo $\mathrm{XIX}^{21}$, se vio obligado a penetrar en el secreto de pueblos completamente dispares de los europeos y mediterráneos, teniendo, como dice Ortega,

que intimar con sus modos de pensar y sentir. Poco a poco fue advirtiendo que aquellos usos «bárbaros»y aun «salvajes», aquellas ideas grotescas o absurdas, tenían un profundo sentido, una exquisita cohesión. Eran, a la postre, una manera de responder al cosmos circundante muy distinta de la nuestra, pero no menos respetable. Eran, en suma, otras culturas. Gracias a la etnología, el singular de la cultura se ha pluralizado, y al pluralizarse ha perdido su empaque normativo y trascendente [...]. Hay una cultura china y una cultura malaya y una cultura hotentote, como hay una cultura europea. La única superioridad definitiva de esta habrá de ser reconocer esa esencial paridad antes de discutir cuál de ellas es la superior. El hotentote, en cambio, cree que no hay más cultura que la hotentote (Las Atlántidas, OC, III: 756-757) ${ }^{22}$.

Ortega, por tanto, acaba reconociendo a los pueblos tradicionalmente denominados salvajes o bárbaros su lugar en la historia universal, así como también considera en estos momentos que la barbarie entendida como potencia precultu-

21 Ortega conocía los avances que en aquella época se producían en el campo de la etnología, pues ofrece en sus Obras completas múltiples ejemplos al respecto, así como también debatió aquel las corrientes antropológicas de su tiempo, el evolucionismo, el particularismo histórico, el difusionismo o el funcionalismo, refiriéndose a autores tan dispares en algunos aspectos como Bachofen, Frobenius, Ratzel, Bastian o Malinowski. Véase a este respecto el completo estudio de De Haro (2012): 217-240.

22 Que el hotentote crea que su cultura es la única, confirma que el etnocentrismo no es exclusivo de la Europa occidental, sino que se trata de un universal cultural que es como se entiende desde el campo de la antropología social. 
ral engendra toda realidad cultural. En Notas del vago estío, de 1925, dice Ortega:

El vocablo «barbarie», en su uso más frecuente, se ha vaciado de significación propia y conserva solo un sentido peyorativo de descalificación. Lo mismo pasa con la palabra «salvaje». Se olvida que una y otra significan dos tipos de espiritualidad que constituyen dos estadios ineludibles del desarrollo histórico [...]. Es una equivocación desdeñar la barbarie y el salvajismo. Fuera más discreto prestar suma atención a esta gran perogrullada: la civilización es hija de la barbarie y nieta del salvajismo. Comprendo que las épocas privadas de sentido histórico, incapaces de ver en toda realidad su evolución y su génesis, se quedasen solo con la forma civilizada de la vida y no supiesen descubrir en la forma bárbara más que valores negativos. Sería, en efecto, deplorable que el hombre culto abandonase su cultura y se tornase otra vez bárbaro. Pero acaso tenga un excelente sentido decir que la actitud más perfecta consiste en que el hombre culto conserve vivaz cierto fondo de barbarie [...]. Esta mesurada defensa de la barbarie podrá juzgarse una paradoja o una sutileza; pero, en rigor, es una verdad simplicísima, tan clara como humilde. Se reduce, en definitiva, a hacer notar que la cultura no nace de la cultura, sino de potencias y virtudes preculturales que dan en ella su fruto. Toda cultura tiene su raíz en la barbarie, y toda renovación de la cultura se engendra en ese fondo de barbarie, y cuando este se agota, la cultura se seca, se anquilosa y muere. Es, pues, falso querer lo uno sin lo otro. Quien desee para mañana nueva cultura tiene que asegurar en la Europa de hoy cierto mínimo de virtudes bárbaras (Notas del vago estío, OC, II: 544-545) ${ }^{23}$.

En 1920, en El Quijote en la escuela, Ortega ya había dicho que si llamamos al hombre relativamente exento de especialización -esto es, de cultura y civilización- hombre salvaje, "yo diría que en el hombre culto perdura, como base de sustentación vital, el hombre salvaje, y que el progreso cultural procede paralelamente a un progreso en salvajismo. Esta palabra «salvajismo», cargada con su significación peyorativa, implica ya un error. Llamar salvaje al hombre primitivo porque posee menos

23 En el campo de la antropología ha sido ampliamente estudiado el binomio salvaje o bárbaro frente a civilizado. Véase Shweder (1991). Ni que decir tiene que Ortega se opone a la barbarie desmesurada y, por tanto, destructiva del hombre masa. Censura especialmente el comportamiento del que denomina, "bárbaro especialista". Pero esta cuestión quedaría para otro trabajo. instrumentos materiales, políticos e intelectuales que nosotros, es condenarlo íntegramente. Llamar al hombre actual civilizado significa, de paso, hacer su completa apología". Para Ortega, "la cultura y la civilización, que tanto nos envanecen, son una creación del hombre salvaje y no del hombre culto y civilizado. La vida no organizada crea la organización, y todo progreso de esta, su mantenimiento, su impulsión constante, son siempre obra de aquella (El Quijote en la escuela, OC, II: 407) ${ }^{24}$.

Como estamos viendo, en los años 20, y a través de estas aportaciones, Ortega da un vuelco a su pensamiento. Una situación que aquí hemos denominado como "giro antropológico". El pensador madrileño reconocerá el papel de la barbarie y el salvajismo en la constitución y desarrollo de la cultura y la civilización, así como ya no considerará central en el mapa mundial a la Europa occidental, sino que situará a esta junto a otros espacios o pueblos de los que también destacará su aportación a la historia universal.

El europeísmo culturalista de mocedad deja paso, por tanto, a un pluralismo de culturas, que remite a la idea de lo discontinuo y diferencial que es lo que ha acabado definiendo la contemporaneidad. Ortega reconoce este cambio en el siguiente texto de 1933:

Hace veinticinco años gritaba yo a Gog y Magog que la faz de la historia iba a cambiar: lo presentía ni más ni menos que se presiente un cambio meteorológico. Y esta anticipación no era solo genérica o vaga, sino que se precisaba en la expectación concreta de ciertas ideas y estimaciones. En 1911 di yo una conferencia en el Ateneo de Madrid sobre el pensamiento matemático. Era la hora del más indiscutido triunfo del «continuismo» y «evolucionismo» en matemática, física, biología e historia. No obstante, yo anuncié entonces que surgiría pronto una tendencia al «discontinuismo» en todas esas disciplinas. Hablo ahora de mí como se habla del conejo de Indias que se ha sometido a un experimento (La «socialización» del hombre y la «vuelta» a la naturale$z a, \mathrm{OC}, \mathrm{V}: 257)^{25}$.

24 Resulta también llamativa la siguiente reflexión de Ortega en 1920, pues a través de ella este se distancia del pensamiento evolucionista que asumió en sus primeros años como pensador: "He combatido la tendencia a creer que en la evolución de la cultura cada nuevo estadio suprime el anterior y todos ellos suponen la muerte previa del salvajismo. [...]: Nada más falso" (El Quijote en la escuela, OC, II: 424).

25 Aun cuando Ortega, en este escrito de 1933, menciona la fecha de 1911, "se ha podido comprobar, como ya ha- 


\section{A MODO DE BREVE CONCLUSIÓN. ORTEGA Y SU PROPUESTA DE UNIDAD DE UNA PLANETARIA PLURALIDAD}

Con este trabajo de investigación, hemos tratado de ofrecer las claves para una correcta hermenéutica del pensamiento antropológico de Ortega, el cual es parte de su pensamiento filosófico, al que, en cualquier caso, nos sentimos reclamados para tratar de entender no solo este sino cualquier otro aspecto que en su obra aborde el filósofo madrileño, pues como este dice: "Si una cosa es parte, resulta ininteligible mientras no la refiramos al todo cuya es" (Sobre una nueva interpretación de la historia universal. Exposición y examen de la obra de Arnold Toynbee: A study of History, OC, IX: 1208).

Lo que hemos tratado de hacer con la elaboración de este trabajo es precisamente estudiar las ideas antropológicas de Ortega -su reflexión sobre la humanidad ${ }^{26}$, la historia y la cultura tanto a nivel particular como universal- en los dos diferentes periodos de su producción, refiriendo aquellas ideas -como la parte al todo- al pensamiento filosófico que define cada uno de aquellos periodos. Pero sobre todo hemos incidido en el tránsito entre un periodo y otro, lo que hemos denominado "giro antropológico" que es la principal aportación de este artículo de investigación.

En un primer momento, un Ortega inmerso en un ambiente europeísta y neokantiano culturalista, sobrevalora el tipo de racionalidad -científica y moral- que caracterizaba a la modernidad, a la que el filósofo se adhiere en su mocedad, pero que luego rechazará. La razón moderna científica es entonces la razón dominante en su filosofía, pero también en su antropología europeísta/germanista y culturalista. La cultura europea, que representa Alemania, pero que hinca sus raíces en Grecia,

bía hecho Garagorri, que esa conferencia se pronunció en 1914 [...] con el título de La matemática como función de la cultura" (Véase Sobre ensimismarse y alterarse, en "Notas a la edición", OC, V: 773). Años antes, en Las Atlántidas (1924), Ortega ya se refirió a esta misma cuestión, cuando dice que en 1914 ya advirtió que "al siglo «evolucionista» y, por tanto, unitarista seguiría una época de mayor atención a lo discontinuo y diferencial" (Las Atlántidas, OC, III: 763). Este cambio que anunció se observaría, como hemos visto, más adelante en su propio pensamiento.

26 Ortega tiene una concepción inicial del ser humano principalmente como ser de cultura y razón pura, frente a su concepción más abierta una vez abandonada su mocedad, al entender a aquel como un ser de razón histórica y vital abocado como está a desarrollar en sociedad o colectividad su proyecto de vida personal. es para Ortega la cultura suprema, si bien es verdad que para este será la cultura clásica griega que recupera la tradición filosófica alemana a través de autores como Leibniz o Kant, la cultura auténtica, verdadera o esencial frente a lo que serían otros pueblos no europeos que para Ortega se encuentran más próximos a la naturaleza que a la cultura cuyo paradigma -de esta última- viene representado por la razón científica y el ideal moral. Esta forma de pensamiento es claramente etnocéntrica y aboca a Ortega a aquello que luego criticará, a saber: el monismo cultural.

Sin embargo, con el paso de los años, sobre todo cuando Ortega se declare en 1916 como nada moderno, pero muy siglo XX, abandonará aquel el pensamiento de la Modernidad y el eurocentrismo racionalista e idealista que profesaba en su mocedad. La cultura europea ya no será la única cultura auténtica o verdadera, sino que Ortega, recurriendo a los datos que aportan nuevas ciencias como la arqueología, la prehistoria y la etnología, se decantará por el pluralismo cultural frente al monismo inicial, siendo esta la hipótesis de trabajo que creemos haber demostrado en este trabajo sobre la obra del filósofo de la razón vital.

En El Sol, el 10 de julio de 1924, comienza Ortega a dudar de que solamente nuestra cultura sea, como se ha venido creyendo, la única merecedora de tal nombre:

Desde hace más de treinta años han comenzado a levantarse graves objeciones contra ese monismo cultural, hasta el punto que será difícil hallar en todo este período un solo historiador de nota que lo acepte [...]. Las ampliaciones gigantescas que ha recibido la ciencia de la historia con el descubrimiento de Oriente, con la arqueología, la etnología y la prehistoria, hacían ineludible una nueva ideología con más largas y rigorosas perspectivas. De todo ese inmenso trabajo que ha sido hecho y hoy continúa han emanado algunos ensayos de síntesis popular. Tales son los sistemas de Frobenius y Spengler ${ }^{27}$.

Ortega tiene claro, como dice en este texto de 1924, que la validez exclusiva de nuestra cultura "es, pues, de hecho cosa muy problemática". Es, de hecho, problemático, dice el filósofo:

\footnotetext{
27 Las reflexiones de Ortega sobre las aportaciones de Frobenius y Spengler, lo que con ellos comparte, pero también lo que de ellos le distancia, así como sus ideas sobre otros autores de la época, han sido estudiadas por De Haro (2012), y por tanto no vamos a incidir en ello, al margen de que escaparía a los objetivos de este trabajo.
} 
... que la nuestra sea la única. A nuestra afirmación de ella contraponen su distinto fervor otras razas hoy deprimidas que un tiempo fueron preponderantes y muy bien podrían volverlo a ser. Para reconocer que las normas y valores vigentes en nuestras almas son los únicos merecedores de tal dignidad, sería menester demostrarlo. Mas para esto haría falta precisamente hacerse de ellos problema. Entonces, y solo entonces, tendríamos algo incomparable a las demás culturas [...]. De donde resulta que nuestra cultura solo será, en efecto, la única auténtica en la medida en que crea que no lo es y se vuelva problemática. Nuestra cultura aparece, por lo pronto, como uno de tantos hechos históricos. Ella misma es un proceso temporal, una germinación apasionada llena de peripecias y aventuras, de adquisiciones, ensayos y fracasos. De aquí que la razón queda incompleta si se reduce a ser razón matemática o lógica. Precisamente lo que necesitamos hoy añadir a la antigua razón es la razón histórica, el sentido histórico. Y este nos lleva irremediablemente a tratar con los negros y los mastodontes (El sentido histórico, OC, III: 696 y ss.).

Ortega relativiza en los primeros años de la década de 1920 la posición de la cultura occidental en el mapa mundial y en la historia universal, frente a lo que consideraba en su pensamiento de mocedad, una época en que concedía exclusividad a la cultura europea en detrimento de otros pueblos que consideraba más próximos a la naturaleza. La incorporación del sentido histórico a su pensamiento resulta, por tanto, fundamental, pues conduce a Ortega a corregir su posición etnocéntrica inicial reconociendo al mismo tiempo la idea de pluralidad y/o diversidad -las diferencias en el terreno de lo cultural-que es la que caracteriza la contemporaneidad: "Hasta ahora, dice Ortega en 1924, el mundo de lo que tiene sentido se reducía a nuestra época y a un pequeño círculo de pueblos afines [...]. Tal privilegio del «tener sentido» se extenderá pronto a los pueblos y edades más diversos y remotos" (Las Atlántidas, OC, III: 771), así como también dice el filósofo español que, "el sentido histórico, comienza cuando se sospecha que la vida humana en otros tiempos y pueblos es diferente de lo que es en nuestra edad y en nuestro ámbito cultural. La diferencia es la distancia cualitativa. El sentido histórico percibe esta distancia psicológica que existe entre otros hombres y nosotros". Esto indica que "el sentido histórico progresa en la medida en que va admitiendo menos cosas co- munes entre el ayer y el hoy, entre el hombre de nuestro círculo histórico y el de otros círculos históricos" (Las Atlántidas, OC, III: 767) ${ }^{28}$.

Resumiendo, en el pensamiento de Ortega se produce, antropológicamente hablando, un cambio sustancial que el filósofo sistematiza en los años 20, cuando modifica su pensamiento culturalista y europeísta de mocedad, asumiendo, por el contrario, un punto de vista pluralista que gira en torno a las ideas del "sentido histórico" y de cultura, y que se concreta en una idea del clasicismo no corto de miras como en ocurría en sus primeros años, sino en un clasicismo universal como podemos observar en El Sol, el 16 de abril de 1924, en un trabajo con título, Las ideas de León Frobenius, donde Ortega dice lo siguiente:

Si existe una cultura que pueda considerarse la ejemplar, la única verdaderamente tal, habrá de poseer finamente acusada la dimensión del sentido histórico. Esto significa que para ser efectiva la Cultura, con mayúscula, hace falta llegar a ella al través y previo el reconocimiento de las otras culturas con minúscula, de todas las de hoy y todas las de ayer. En el momento de este gran estudio, de esta urgente experiencia nos hallamos, y es un poco inocente, un mucho utópico y un demasiado escolar, proponernos una vez más, como salvación, el perfil de Pitágoras y el busto de Euclides. En mi último libro llamaba yo a la geometría de Euclides, puesto que solo vale para las realidades más próximas, geometría provinciana. Preferirla a todas las demás es un mero capricho, y el capricho solo invita al desdén. El clasicismo de que a algunos oigo hablar, suena a norma de provincia, y, en efecto, se origina en un dulce romanticismo de subprefectura. Ahora se trata de buscar un clasicismo de radio mayor, la unidad de una planetaria pluralidad, algo que germina en estos versos de Goethe: De Dios es el Oriente, de Dios el Occidente; las tierras de Norte y Sur descansan en la paz de sus manos (Las ideas de León Frobenius, OC, III: 662).

28 Ortega se está aquí distanciando del pensamiento unitarista y evolucionista de la época que iba dejando atrás: "En general, el espíritu evolucionista, tan característico del siglo pasado, tiende a ignorar las diferencias y a subrayar lo que hay de común entre las cosas" (Las Atlántidas, OC, III: 768). Véase la edición crítica sobre Las Atlántidas (1924) y otros textos de antropología de Ortega, realizada por J. R. Carriazo (2015). 


\section{BIBLIOGRAFÍA}

Cassirer, E., Cohen, H. y Natorp, P. (1998). L'École de Marburg, préface par M. Ferrari, París: Les Éditons du Cerf.

Dilthey, W. (1986). Crítica de la razón histórica, Barcelona: Península.

Gadamer, H.-G. (1985). "Ortega y Dilthey”, Revista de Occidente, $\mathrm{n}^{\text {os }} 48-49$, pp. 77-88.

Haro Honrubia, A. de (2012). "La Antropología Social en la obra de Ortega. Su contribución a la etnografía moderna", Anales del Seminario de Historia de la Filosofía, vol. 29, n 1, pp. 217-240.

Lowie, R. H. (1946). Historia de la etnología, México: Fondo de Cultura Económica.

Kant, I. (1989). La metafísica de las costumbres, traducción y notas de A. Cortina Orts y J. Conill Sancho, Madrid: Tecnos,

Ortega y Gasset, J. (2004-2010). Obras completas; Madrid: Taurus/Fundación José Ortega y Gasset (10 tomos).

Ortega y Gasset, J. (1990). Cartas de un joven español (1891-1908), edición de S. Ortega, Madrid: Ediciones el Arquero.
Ortega y Gasset, J. (2015). Las Atlántidas y otros textos antropológicos, edición de J. R. Carriazo, Madrid: Tecnos.

Platón (1914): Platonis Euthyphro; Apologia Socratis; Crito; Phaedo / post Carolum Fridericum Hermannum; recognovit Martinus Wohlrab. Ed. Stereotypa, Lipsiae: B. G. Teubneri, Steingaden.

Platón (1920-1985). Oeuvres complètes; texte établi et traduit par M. Croiset; París: "Les Belles Lettres".

Platón (1931). Platón el divino: diálogos platónicos / traducción directa por E. Mazorriaga; Madrid: Librería y Casa Editorial Hernando.

San Martín, J. (2009). Para una superación del relativismo cultural. Antropología cultural y Antropología filosófica, Madrid: Tecnos.

Shweder, R. A. (1991). "La rebelión romántica de la antropología contra el iluminismo, o el pensamiento es más que razón y evidencia”, en $\mathrm{C}$. Reynoso, comp., El surgimiento de la antropología posmoderna, México: Editorial Gedisa, pp. 78-113. 